\title{
Pengaruh Silica Fume sebagai Subtitusi Semen terhadap Nilai Resapan dan Kuat Tekan Mortar
}

\author{
BANTOT SUTRIONO, RETNO TRIMURTININGRUM, ADITYA RIZKIARDI
}

\author{
Fakultas Teknik, Universitas 17 Agustus 1945, Surabaya \\ Email: bantot@untag-sby.ac.id
}

\begin{abstract}
ABSTRAK
Beton dan mortar banyak digunakan sebagai bahan konstruksi di seluruh dunia. Meningkatnya permintaan beton dan mortar juga meningkatkan permintaan semen di pasar yang berdampak negatif bagi lingkungan. Industri semen menghasilkan sekitar 6 hingga 7 persen dari seluruh $\mathrm{CO}_{2}$ di seluruh dunia. Oleh karena itu, para peneliti mencoba mengembangkan gagasan tentangbeton ramah lingkungan, dengan mengurangi penggunaan semen dengan menggunakan bahan alternatif seperti silica fume. Silica fume adalah bahan pozzolan yang kaya akan silika dan dapat bereaksi kimia dengan kalsium hidroksida, membentuk gel kalsium silikat (CSH) pada beton. Tujuan dari penelitian ini adalah untuk menyelidiki pengaruh silica fume sebagai pengganti parsial semen terhadap nilai resapan dan kekuatan tekan mortar. Persentase silica fume bervariasi 0\%, 5\%, $10 \%, 12 \%$ dan 15\%. Hasil pengujian menunjukkan nilai resapan minimum adalah 3,276\% diperoleh campuran dengan $15 \%$ silica fume dan kuat tekan maksimum $312,574 \mathrm{~kg} / \mathrm{cm}^{2}$ diperoleh campuran dengan $8 \%$ silica fume.
\end{abstract}

Kata kunci: silica fume, nilai resapan, kuat tekan, mortar

\begin{abstract}
Concrete and mortar are widely used as contruction materials. The increasing demand of concrete and mortar also increase the demand of cement in the market which has negative impact for environment. The cement industry produced for approximately 6 to 7 percent of all $\mathrm{CO}_{2}$ worldwide. Therefore, the researches try to develop the idea of green concrete with reducing the utilize of cement with using the alternative materials such as silica fume. Silica fume is a pozzolanic material that contain rich of silica and has chemical reaction with calcium hydroxide forming calcium silicate hydrate (C-S-H) gel in concrete. The aimed of this research is to investigate the influence of silica fume as partial replacement of cement on absoption and compressive strength of mortar. The percentage of silica fume were varied from $0 \%, 5 \%, 10 \%, 12 \%$ and $15 \%$. The test result showed that the minimum absorption value is $3.276 \%$ obtain from the mixture with $15 \%$ of silica fume and the maximum compressive strength is $312.574 \mathrm{~kg} / \mathrm{cm}^{2}$ obtain from the mixture with $8 \%$ of silica fume.
\end{abstract}

Keywords: Silica fume, absorption, compressive strength, mortar 


\section{PENDAHULUAN}

Beton dan juga mortar merupakan material konstruksi yang sangat banyak digunakan saat ini. Pada tahun 2002, produksi material beton sendiri mencapai 2,7 milyar $\mathrm{m}^{3}$ (Gautam et al, 2014) dan akan semakin berkembang pesat setiap tahunnya. Kebutuhan material beton dan mortar yang semakin meningkat berbanding lurus dengan kebutuhan produksi semen, karena semen merupakan salah satu material penyusun beton yang bersama-sama dengan air berfungsi sebagai perekat/binder. Proses produksi semen inilah yang berdampak buruk terhadap lingkungan. Produksi satu ton semen Portland diperkirakan berkontribusi melepaskan satu ton $\mathrm{CO}_{2}$ yang juga dikenal sebagai gas emisi rumah kaca (Meyer, 2009 and Meyer, 2013). Produksi semen berperan sebesar 6-7\% pada pembentukan $\mathrm{CO}_{2}$ di dunia (Meyer, 2009 and Meyer, 2013). Hal tersebutlah yang menjadi pendorong para peneliti untuk dapat membuat beton yang lebih ramah lingkungan atau lebih dikenal dengan istilah "Green Concrete".

Salah satu cara untuk membuat campuran beton lebih ramah lingkungan adalah dengan mengurangi penggunaan semen dalam produksi beton. Material alternatif yang biasa digunakan sebagai pengganti sebagian semen adalah material yang mempunyai sifat pozolan. Pozolan adalah material yang mengandung senyawa silika dan alumina dan dapat bereaksi secara kimiawi dengan kalsium hidroksida (senyawa hasil reaksi antara semen dengan air) membentuk senyawa calsium silicate hydrate (C-S-H) dan calcium aluminate hydrate (C-A-H), sehingga mempunyai sifat seperti semen (ACI 116R-00). Pozolan terbagi menjadi dua jenis yaitu pozolan alami dan pozolan buatan. Contoh material pozolan antara lain adalah trass yang merupakan pozzolan alami serta slag, fly ash dan silica fume yang merupakan pozolan buatan.

Silica fume merupakan material halus yang kaya akan silika dan merupakan hasil samping dari industrisilicon ferro (ACI234.R-06). Silica fume berwarna abu-abu dan mempunyai diameter berukuran antara 0,1 sampai 0,2 micron meter atau sekitar 1/100 ukuran semen (ACI234.R-06) (Gambar 1). Karena material silica fume merupakan hasil samping industri, maka material tersebut relatif mudah untuk didapatkan. Berdasarkan penelitian sebelumnya, penggunaan silica fume dapat mempengaruhi sifat-sifat beton seperti: meningkatkan kuat tekan dan durabilitas beton karena dapat memperkecil volume pori di dalam beton. Hal tersebut disebabkan karena silica fume mempunyai efek pozolan dan inert filler yang dapat mengisi rongga antara pasta semen dengan agregat.

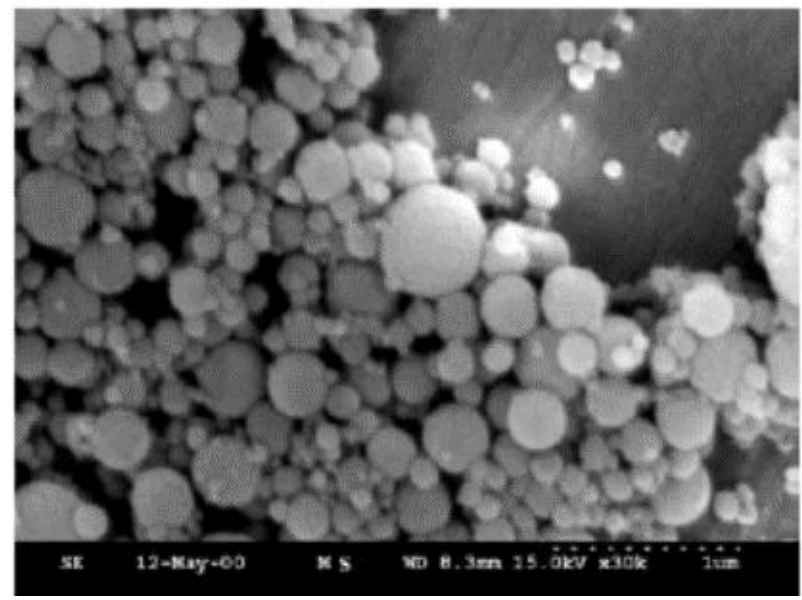

Gambar 1 Silica fume dilihat secara mikroskopik (Sumber: McGraw Hill, 2006) 


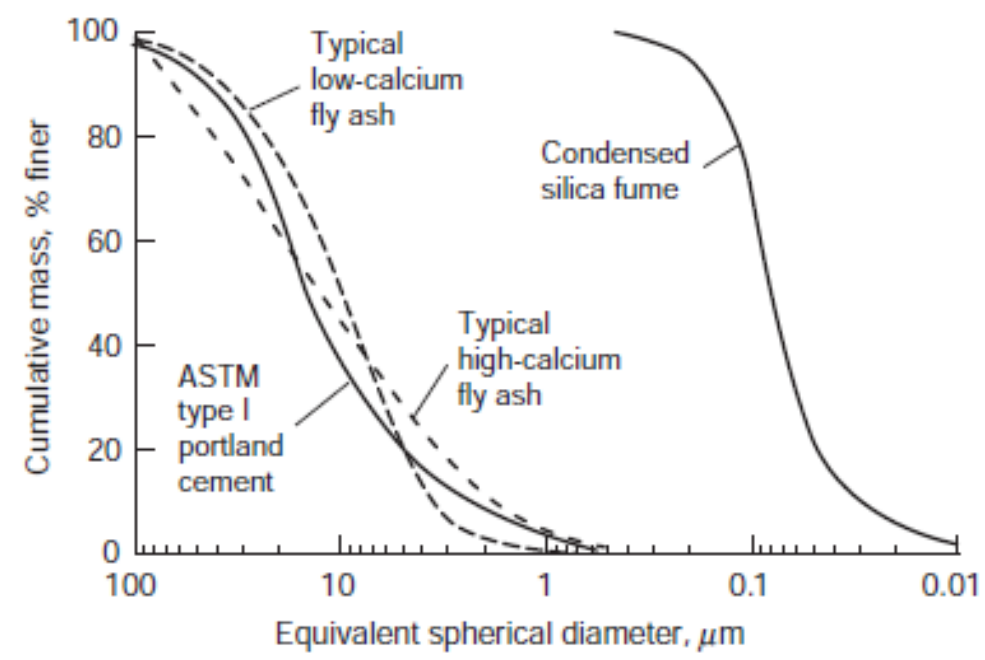

Gambar 2. Perbandingan ukuran distribusi partikel antara semen, fly ashd an silica fume (Sumber: McGraw Hill, 2006)

Oleh karena itu, dalam penelitian ini, peneliti akan menggunakan material silica fume sebagai bahan subtitusi sebagian semen dengan menggunakan mortar sebagai benda uji. Mortar adalah campuran dari pasta semen yang berfungsi sebagai binder dan agregat halus yang berfungsi sebagai filler. Variasi silica fume yang digunakan adalah $0 \%, 5 \%, 8 \%, 12 \%$, dan $15 \%$ terhadap berat cementitious.

\section{METODOLOGI PENELITIAN}

\section{Diagram Alir Penelitian}

Tahapan penelitian dapat dilihat dari diagram alir penelitian pada Gambar $\mathbf{3}$ di bawah ini:

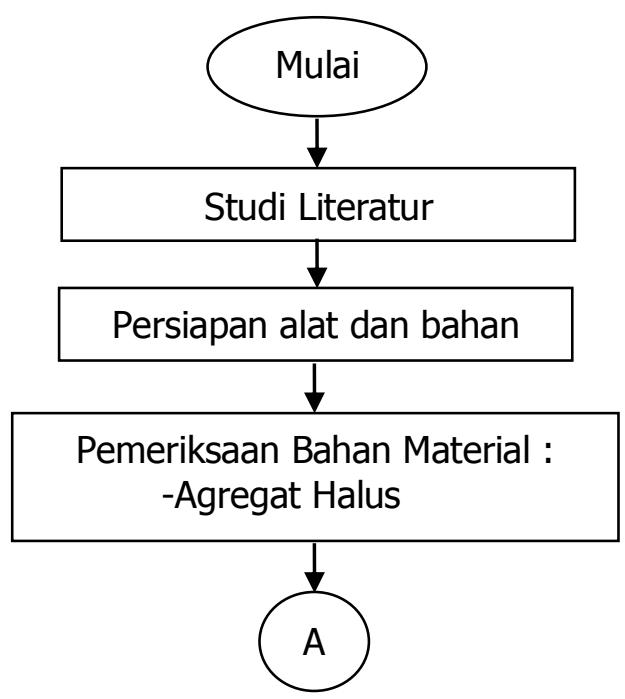

Gambar 3. Diagram alir penelitian 


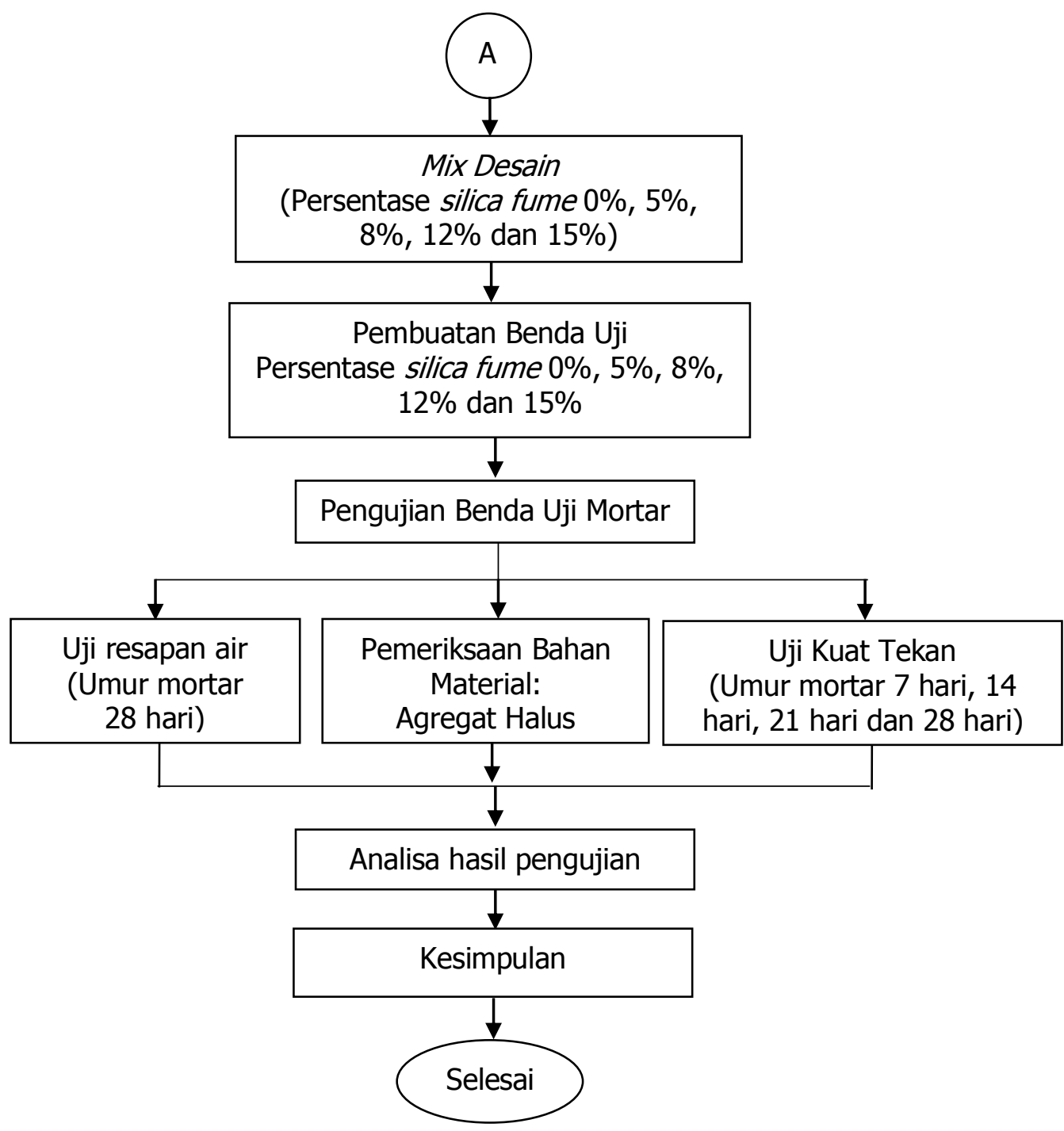

Gambar 3. Diagram alir penelitian (lanjutan)

\section{Material}

- Semen

Semen yang digunakan adalah semen Portland Gresik Tipe 1.

- Agregat Halus (Pasir)

Pasir yang digunakan adalah pasir alami dari Kabupaten Lumajang, Jawa Timur.

- Air PAM

Air PAM berasal dari lingkungan Laboratorium Teknologi Beton Teknik Sipil Universitas 17 Agustus 1945 Surabaya. Penggunaan air PAM ini untuk campuran beton dan proses curing.

- Silica Fume

Silica Fume ini berasal PT. SIKA INDONESIA.

\section{Proporsi Campuran Benda Uji Mortar}

Perhitungan mix design benda uji mortar mengacu pada SNI 03-6825-2002 tentang "Metode Pengujian Kuat Tekan Mortar Semen Portland untuk Pekerjaan Sipil". SNI 03-6825-2002 mengatur untuk pembuatan 6 benda uji berbentuk kubus dengan ukuran sisi $5 \mathrm{~cm}$ menggunakan komposisi diantaranya adalah: 
Semen Portland 500 gram, Pasir 1.375 gram,

Air $242 \mathrm{ml}$.

Proporsi tersebut kemudian disesuaikan dengan ukuran dan volume benda uji mortar dalam penelitian ini. Sehingga didapatkan kebutuhan proporsi material seperti yang dijabarkan pada Tabel 1 dan Tabel 2.

Tabel 1. Proporsi Campuran Mortar untuk 6 Benda Uji Silinder Ukuran Diameter $6 \mathrm{~cm}$ dan Tinggi $12 \mathrm{~cm}$

\begin{tabular}{ccccc}
\hline $\begin{array}{c}\text { Jenis } \\
\text { Campuran }\end{array}$ & $\begin{array}{c}\text { Semen } \\
\text { [gram] }\end{array}$ & $\begin{array}{c}\text { Pasir } \\
\text { [gram] }\end{array}$ & $\begin{array}{c}\text { Silica } \\
\text { Fume } \\
\text { [gram] }\end{array}$ & $\begin{array}{c}\text { Air } \\
\text { [mI] }\end{array}$ \\
\hline SF - 0 & $1.356,48$ & $3.730,32$ & - & 656,54 \\
\hline SF - 5 & $1.288,66$ & $3.730,32$ & 67,82 & 656,54 \\
\hline SF - 8 & $1.247,96$ & $3.730,32$ & 108,52 & 656,54 \\
\hline SF - 12 & $1.193,70$ & $3.730,32$ & 162,78 & 656,54 \\
\hline SF - 15 & $1.153,01$ & $3.730,32$ & 203,47 & 656,54 \\
\hline
\end{tabular}

Tabel 2. Proporsi Campuran Mortar Setiap Benda Uji

\begin{tabular}{ccccc}
\hline $\begin{array}{c}\text { Jenis } \\
\text { Campuran }\end{array}$ & $\begin{array}{c}\text { Semen } \\
\text { [gram] }\end{array}$ & $\begin{array}{c}\text { Pasir } \\
\text { [gram] }\end{array}$ & $\begin{array}{c}\text { Silica } \\
\text { Fume } \\
\text { [gram] }\end{array}$ & $\begin{array}{c}\text { Air } \\
{[\mathrm{ml}]}\end{array}$ \\
\hline SF - 0 & 226,08 & 621,72 & - & 109,42 \\
\hline SF - 5 & 214,78 & 621,72 & 11,30 & 109,42 \\
\hline SF - 8 & 207,99 & 621,72 & 18,09 & 109,42 \\
\hline SF - 12 & 198,95 & 621,72 & 27,13 & 109,42 \\
\hline SF - 15 & 192,17 & 621,72 & 33,91 & 109,42 \\
\hline
\end{tabular}

Terdapat 5 (lima) macam campuran dalam penelitian ini yang dibedakan berdasarkan jumlah presentase silica fume yang digunakan. Presentase silica fume yang digunakan adalah $0 \%$, $5 \%, 8 \%, 12 \%$ dan $15 \%$ terhadap berat total cementitious. Jumlah sampel total penelitian 75 buah, seperti yang dijelaskan pada Tabel $\mathbf{3}$.

Tabel 3. Jumlah Total Benda Uji Mortar

\begin{tabular}{|c|c|c|c|c|c|}
\hline \multirow{2}{*}{$\begin{array}{c}\text { Kode } \\
\text { Campuran }\end{array}$} & \multicolumn{4}{|c|}{ Tes Kuat Tekan } & \multirow{2}{*}{$\begin{array}{c}\text { Tes Resapan Air } \\
28 \text { Hari }\end{array}$} \\
\hline & 7 Hari & 14 Hari & 21 Hari & 28 Hari & \\
\hline SF-0\% & 3 & 3 & 3 & 3 & 3 \\
\hline SF-5\% & 3 & 3 & 3 & 3 & 3 \\
\hline SF- $8 \%$ & 3 & 3 & 3 & 3 & 3 \\
\hline SF-12\% & 3 & 3 & 3 & 3 & 3 \\
\hline SF-15\% & 3 & 3 & 3 & 3 & 3 \\
\hline Jumlah & & & & 75 & \\
\hline
\end{tabular}

Benda uji yang digunakan berupa mortar dengan cetakan berbentuk silinder berukuran diameter $6 \mathrm{~cm}$ dan tinggi $12 \mathrm{~cm}$ (Gambar 4). dengan perawatan direndam ke dalam bak curing dalam temperatur ruangan selama waktu pengujian, yaitu 7 hari, 14 hari, 21 hari dan 28 hari (Gambar 5). 


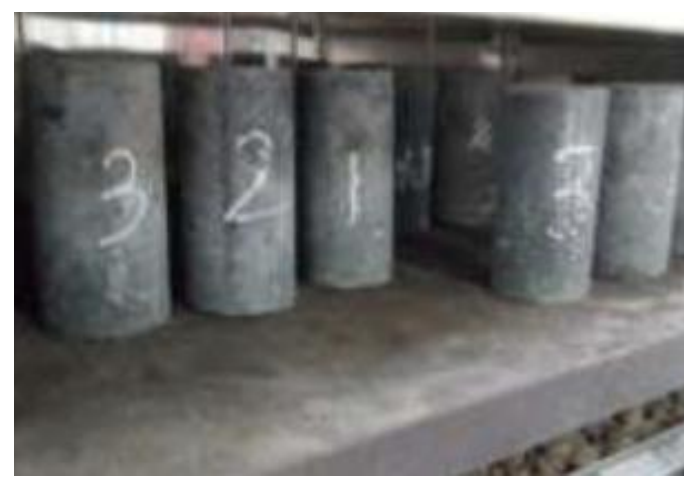

Gambar 4. Benda uji mortar

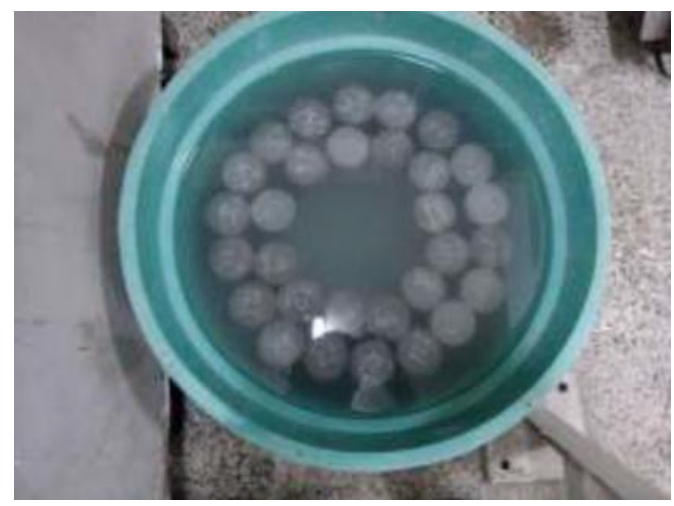

Gambar 5. Proses curing benda uji mortar

\section{Pengujian Benda Uji Mortar}

\section{Air Resapan Mortar}

Pengujian daya serap air pada mortar menggunakan mortar yang telah memenuhi persyaratan secara bentuk fisik. Pengujian ini bertujuan agar mengetahui kemampuan resapan air dari mortar yang berhubungan dengan volume pori yang terdapat pada benda uji. Pengujian dilakukan di Laboratorium Beton Universitas 17 Agustus 1945 Surabaya. Pengujian dilakukan dengan merendam benda uji ke dalam air selama 24 jam untuk kemudian ditimbang beratnya, lalu mengeringkan benda uji dengan dimasukkan ke dalam oven selama 24 jam dan ditimbang kembali beratnya.

Perhitungan air resapan mortar adalah sebagai berikut (Persamaan 1):

$$
\text { Air resapan mortar }=\frac{m_{b}-m_{k}}{m_{k}} * 100 \%
$$

halmana:

$m_{b} \quad=$ massa kering jenh permukaan dari benda uji [gram],

$m_{k} \quad=$ massa kering oven dari benda uji [gram].

\section{Kuat Tekan Mortar}

Pengujian ini bertujuan untuk mengetahui kekuatan tekan dari benda uji mortar. Pengujian dilakukan di Laboratorium Beton Universitas 17 Agustus 1945 Surabaya (Gambar 6). 
Sebelum dilakukan pengujian, terlebih dahulu meratakan permukaan penampang benda uji agar seluruh permukaan dapat menerima beban yang seragam.

Perhitungan kuat tekan adalah (Persamaan 2):

$$
\sigma_{m}=\frac{P_{m a k s}}{A}
$$

halmana:

$\sigma_{m} \quad=$ kekuatan tekan mortar [MPa],

$P_{\text {maks }}=$ gaya tekan maksimum $[\mathrm{kg}]$,

$A \quad=$ luas penampang uji $\left[\mathrm{cm}^{2}\right]$.

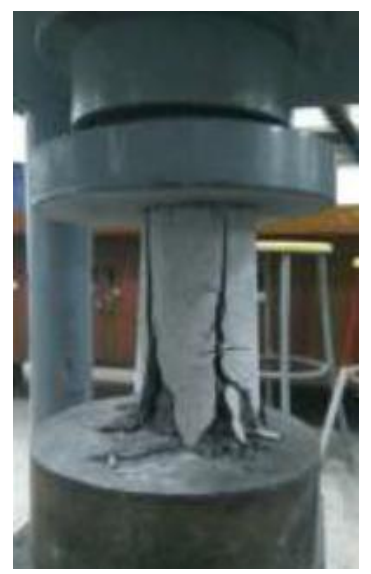

Gambar 6. Pengujian tekan

\section{HASIL DAN PEMBAHASAN}

\section{Hasil Pengujian Resapan Air Mortar}

Pengaruh prosentase silica fume sebagai material pengganti sebagian semen dalam campuran mortar terhadap nilai resapan air dapat dijelaskan pada Gambar 7.

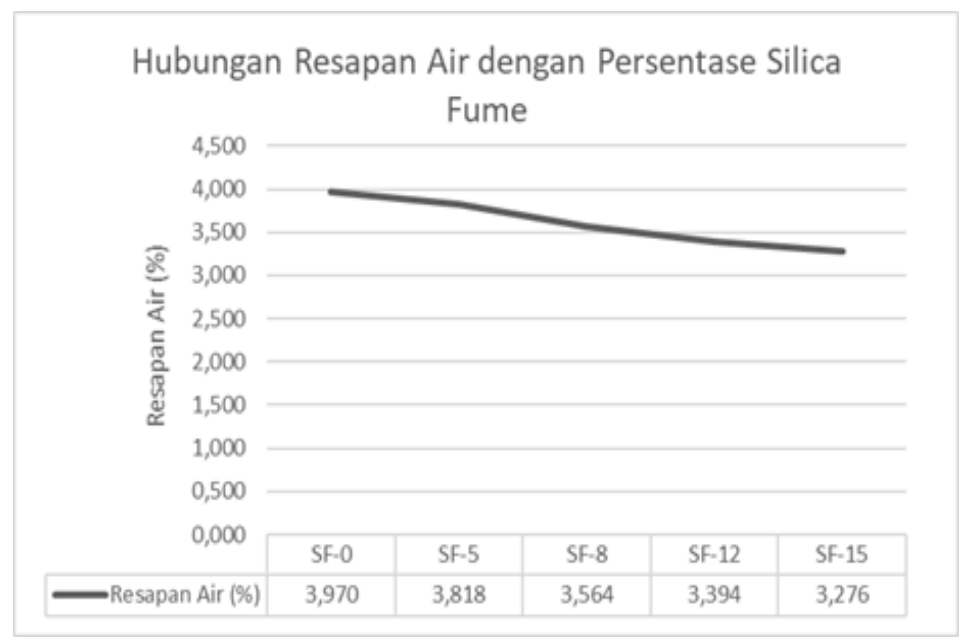

Gambar 7. Pengaruh prosentase silica fume terhadap nilai resapan mortar 
Gambar 7 menunjukkan bahwa persentase silica fume berpengaruh pada nilai resapan air benda uji mortar. Dari grafik pada Gambar 7 dapat terlihat bahwa semakin besar persentase silica fume maka nilai resapan air semakin kecil. Nilai resapan maksimum yaitu sebesar 3,970\% didapatkan pada benda uji kontrol dengan $0 \%$ kandungansilica fume. Nilai resapan air minimum yaitu 3,276\%, mengalami penurunan sebesar $17,5 \%$ diperoleh benda uji dengan persentase silica fume $15 \%$. Hal tersebut karena silica fume mempunyai dua peranan di dalam campuran mortar benda uji. Efek pozolan yang ditimbulkan karena reaksi senyawa silika dalam silica fume dengan kalsium hidroksida membentuk gel CSH baru, dimana gel CSH tersebut berkembang pada rongga di antara pasta semen dengan agregat sehingga menyebabkan berkurangnya volume pori yang terdapat dalam benda uji. Selain itu, efek microfiller pada silica fume juga mempunyai peranan yang sangat penting. Kelebihan silica fume yang tidak bereaksi dengan kalsium hidroksida berfungsi sebagai filler atau pengisi rongga di dalam campuran benda uji, sehingga membuat benda uji lebih padat dan kedap. Berkurangnya volume pori serta benda uji yang lebih padat dan kedap menyebabkan nilai resapan air semakin berkurang.

\section{Hasil Pengujian Kuat Tekan Mortar}

Pengaruh prosentase silica fume sebagai material pengganti sebagian semen dalam campuran mortar terhadap kuat tekan dapat dijelaskan Gambar 8 dan Gambar 9.

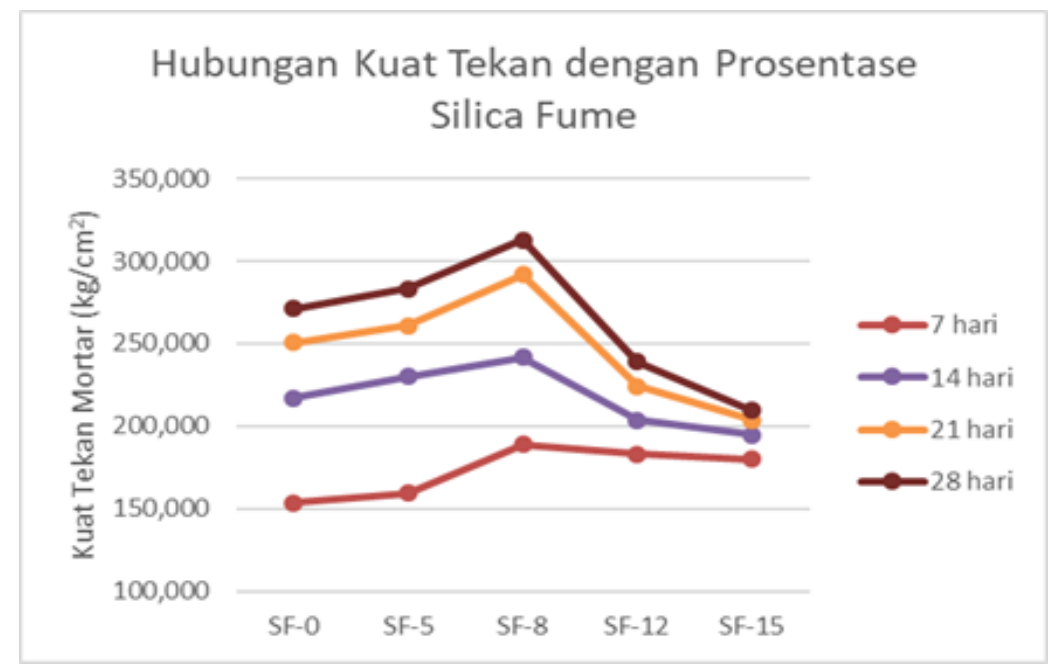

Gambar 8. Pengaruh prosentase silica fume terhadap kuat tekan mortar

Gambar 8 menunjukkan bahwa persentase silica fume berpengaruh pada kuat tekan mortar. Benda uji mortar pada umur 7 hari, 14 hari, 21 hari dan 28 hari menunjukkan pola yang sama yaitu mempunyai kuat tekan yang meningkat pada persentase silica fume sebesar $5 \%$ dan $8 \%$ dan mengalami penurunan kuat tekan pada campuran dengan persentase silica fume sebesar $12 \%$ dan $15 \%$. 


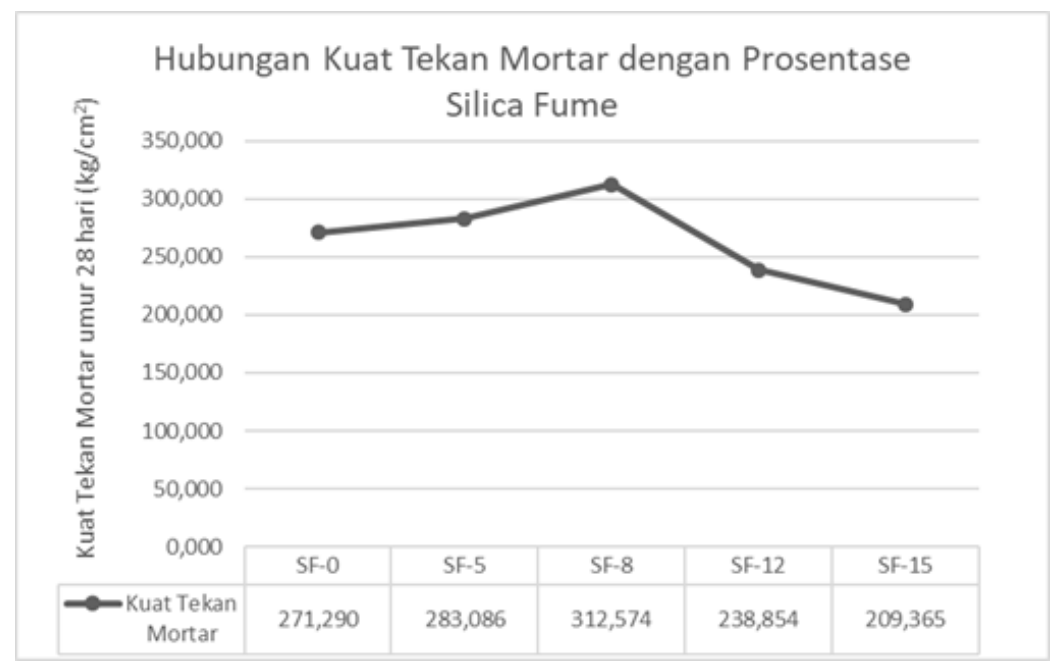

\section{Gambar 9. Pengaruh prosentase silica fume terhadap kuat tekan mortar pada umur 28 hari}

Pada Gambar 9 terlihat bahwa, pada umur mortar 28 hari campuran yang mempunyai kuat tekan maksimum terdapat pada campuran yang memiliki persentase silica fume sebesar $8 \%$, yaitu sebesar $312,574 \mathrm{~kg} / \mathrm{cm}^{2}$. Kuat tekan tersebut mengalami peningkatkan sebesar $3,8 \%$ dari kuat tekan beton kontrol sebesar $271,290 \mathrm{~kg} / \mathrm{cm}^{2}$. Hal tersebut disebabkan karena efek pozzolan yang terdapat pada silica fume. Silica fume bereaksi dengan kalsium hidroksida yang dihasilkan pada reaksi antara semen dan air sehingga membentuk gel calcium silicate hydrate (C-S-H) baru dalam campuran yang dapat meningkatkan ikatan antara pasta semen dengan agregat, selain itu ukuran diameter silica fume yang sekitar $1 / 100$ dari semen mempunyai keuntungan dapat mengisi rongga-rongga pada transition zone yang terdapat antara pasta dengan agregat. Hasil tersebut sesuai dengan penelitian sebelumnya oleh Sriastava et al (2014) yang menyatakan bahwa kenaikan kuat tekan beton disebabkan karena proseskimia dan fisika dimana proses kimia terjadi karena adanya pozzolanic activity dan proses fisika terjadi karena microfiller action.

Kuat tekan terendah didapat pada campuran dengan persentasesilica fume sebesar $15 \%$, yaitu $209,365 \mathrm{~kg} / \mathrm{cm}^{2}$. Penurunan kekuatan tersebut terjadi karena semakin banyak persentase silica fume sebaga bahan pengganti sebagian semen menyebabkan semakin sedikit bahan semen yang bereaks dengan air membentuk gel CSH dan kalsium hidroksida, selain itu persentase silica fume yang banya menyebabkan banyak sisa silica fume tidak bereaksi dengan kalsium hidroksi dan membentuk gel CSH baru dan hanya berfungsi sebagai filler dalam rongga antara pasta semen dengan agregat.

\section{KESIMPULAN}

Nilai resapan air semakin berkurang pada benda uji seiring dengan meningkatnya persentase silica fume. Hal tersebut terjadi karena efek pozolan dan microfiller pada silica fume menyebabkan semakin berkurangnya volume pori pada campuran benda uji sehingga semakin sedikit pula jumlah air yang dapat terserap oleh benda uji.

Silica fume sebagai material pengganti sebagian semen berpengaruh terhadap kuat tekan. Kuat tekan meningkat seiring dengan pertambahan silica fume sampai sebanyak $8 \%$. Hal tersebut disebabkan karena efek pozolan dan microfiller pada silica fume. Kuat tekan maksimum yang didapatkan adalah $312,574 \mathrm{~kg} / \mathrm{cm}^{2}$, pada benda uji $8 \%$ kandungan silica fume. 


\section{UCAPAN TERIMA KASIH}

Peneliti ingin mengucapkan puji syukur kepada Allah SWT, serta terima kasih kepada institusi Universitas 17 Agustus 1945 Surabaya yang telah bersedia memberikan dana dalam penelitian ini; sehingga penelitian ini dapat berjalan dengan baik dan lancar.

\section{DAFTAR RUJUKAN}

ACI Committee 234. (2006). ACI 234R-06 Guide for the Use Silica Fume in Concrete. ACI Committee 234.

ACI Committee 116. (2006). ACI 116R-00 Cement and Concrete Terminology. ACI Committee 116.

Badan Standardisasi Nasional. 2002. SNI 03-6825-2002 tentang Metode Pengujian Kuat Tekan Mortar Semen Portland untuk Pekerjaan Sipil. Jakarta: Badan Standardisasi Nasional.

Gautam, N. et al. (2014). Sustainability in the Concrete Construction. Enviromental Research and Development, 4 (1), 81-90.

Mehta, P. Kumar, Paulo J.M. Monteiro. (2006). Concrete: Microstructure, Properties and Materials. New York: McGraw-Hill.

Meyer, C. (2004). Sustainable Development and the Concrete Industry. Research Gate. https://www.researchgate.net/publication/240611448_Sustainable_Development_and_the _Concrete_Industry.

Meyer, Christian. (2013, Sept 8-12). The Greening of Concrete Industry. In Chang-Koon Choi(Ed.). The 2013 World Congress on Advances in Structural Engineering and Mechanics (ASEM13). pp. 79-92. Jeju: International Convention Centre (ICC) Jeju Korea. ISBN: 97889-89693-39-0.

Sriastava, Vikas et al. (2014). Effect of Silica Fume on Workability and Compressive Strength of OPC Concrete. J. Environ. Nanotechnol , 3 (3) 32-35. 